\title{
FINE ROOTS AND ECTOMYCORRHIZAL COLONIZATION IN BLACK SPRUCE SUBJECTED TO REDUCTIONS IN SOIL MOISTURE
}

\section{Sergio Rossi ${ }^{1,2 *}$, Éliane Couture ${ }^{1}$, Xavier Plante ${ }^{1}$, Hubert Morin ${ }^{1}$}

1 Département des Sciences Fondamentales, Université du Québec à Chicoutimi, Canada

2 Key Laboratory of Vegetation Restoration and Management of Degraded Ecosystems, Provincial Key Laboratory of Applied Botany South China Botanical Garden, Chinese Academy of Sciences, Guangzhou, China

* Corresponding author : Université du Québec à Chicoutimi, 555 Boulevard de l'Université, Chicoutimi (QC), G7H2B1, Canada, tel.: +1-418-545-5011, fax: +1-418-545-5012, sergio.rossi@uqac.ca. 


\begin{abstract}
Growth and survival of boreal tree species depends on fungal symbionts, namely mycorrhizas. Due to their rapid turnover, fine roots and their symbionts can be prompt and sensitive indicators of the effects of environmental changes on forest ecosystems. We investigated how a reduction in soil moisture influences fine roots and ectomycorrhizas (ECM) of black spruce [Picea mariana (Mill.) BSP] after three years of rain exclusion in four mature stands of the boreal forest of Quebec, Canada. Rain was excluded with transparent plastic under-canopy roofs installed during the growing seasons 2010-2012. Soil moisture was strongly affected by the treatment, with water content being reduced from 40 to $21 \%$ on average. As expected, the experimental trees showed a decrease in the proportion of vital root tips and ECM with respect to controls. The proportion of vital ECM was also globally reduced from 73.8 to $68.6 \%$, but the effects of the treatment were significant only in two sites. The expected drier conditions due to current warming will likely influence the presence of mycorrhizas, with potential consequences on the root vitality of boreal tree species.
\end{abstract}

Keywords: boreal forest; climate change; drought; Picea mariana; soil moisture; water stress 


\section{INTRODUCTION}

In Canada, the eastern boreal forest is characterized by short summers with low temperatures and evaporation rates. Rainfall is frequent and well distributed during the growing season, and the soil in flat areas often remains wet or partially submerged. Moreover, the abundant organic matter covered by a thick moss layer can contribute to maintaining high soil moisture during the entire growing season of plants. Boreal species thus grow with abundant water supply and high moisture conditions, and are in some cases well adapted to the reduced aeration of soils in lowland sites with superficial groundwater (Hofgaard et al. 1999; Huang et al. 2010).

Recent observations and current projections indicate that the climate is changing radically, mainly at higher latitudes (IPCC 2013). The southern regions of Canada have experienced increases of $0.9^{\circ} \mathrm{C}$ in the mean annual temperature during the past century (Zhang et al. 2000). In Eastern Canada, warming is associated with an increase in summer precipitation (Zhang et al. 2001; Zhang et al. 2000). In summer, extreme environmental conditions with the occurrence of alternating wet and dry periods are becoming more frequent (Zhang et al. 2000). Timing, duration and extent of changes in temperature and precipitation could modify the evapotranspiration of boreal stands and the water availability for plants and the whole ecosystem (Allison and Treseder 2008). The increase in precipitation may be unable to balance the increase in evaporation induced by warming, causing declines in soil moisture (Easterling et al. 2000; Motha and Baier 2005). How do these changes in the global hydrological cycles affect the ecosystems of higher latitudes?

The survival and growth of tree species in the boreal forest depends on fungal symbionts, namely mycorrhizal fungi (Read et al. 2004). Mycorrhizas are the interface between plant and soil, improving the resource acquisition by roots and increasing defences against stressful conditions for trees. Specific benefits are related to the modification of the water economy of trees though enhancement of drought 
resistance at intermediate levels of water stress (Smith and Read 2008). Annual growth of fine roots can represent up to $56 \%$ of the total production of coniferous stands in Alaska (Ruess et al. 2003). To sustain an abundant colonization of their roots, boreal species allocate high proportions of their photosynthates to the growth metabolism of belowground organs (Read et al. 2004). Moreover, fine roots exhibit high rates of metabolism and account for a significant proportion of ecosystem net primary productivity (Pregitzer et al. 2002). Unlike the tree as a whole, fine roots and mycorrhizas are highly dynamic because their rapid turnover rates enable them to respond directly and rapidly to environmental changes (Deslippe et al. 2011; Ruess et al. 2003; Staddon et al. 2002). They could thus be prompt indicators of alterations that could subsequently affect the other components of the ecosystem, in particular the plants and the organisms involved in nutrient cycling.

Drought is one of the factors that can affect the presence of fungi and mycorrhizas. However, contrasting responses of the rate of mycorrhization to moisture stress have been observed (Lehto and Zwiazek 2011). Drought was reported to either enhance (Davies et al. 1996; Swaty et al. 1998) or reduce (Becker et al. 1987) the proportion of mycorrhizal root tips. The aim of this study was thus to investigate how a reduction in soil moisture influences fine roots and ectomycorrhizas (ECM) in the boreal ecosystem. A rain exclusion experiment was performed over three consecutive years in four mature stands in the boreal forest of Quebec, Canada. Black spruce [Picea mariana (Mill.) BSP] was used as representative species due to its ecological and economic importance stemming from its transcontinental distribution in northern North America and ability to grow under very wet conditions (Lamhamedi and Bernier 1994). The roots of this species were consequently expected to be sensitive to reductions in soil moisture. It was hypothesized that the proportion of living fine roots and ECM located in the superficial soil layers would decline with moisture stress. 


\section{MATERIAL AND METHODS}

\section{Study sites}

Four permanent sites [Simoncouche (abbreviated as SIM), Bernatchez (BER), Mistassibi (MIS) and Camp Daniel (DAN)] were identified in monospecific black spruce stands of 80-100 years old within the coniferous boreal forest of Quebec, Canada (Table 1). According to the climatic data assessed using BioSIM version 10.3 (Natural Resources Canada, Sainte-Foy), the region has a typical boreal climate with cold winters and cool summers and a mean annual temperature of $-2.1-0.9{ }^{\circ} \mathrm{C}$. Precipitation is generally abundant and homogeneously distributed during the growing season, and ranges between 1006 and $1162 \mathrm{~mm}$ (Rossi 2015). The sites have long winters, with the coldest temperature reaching $44.8^{\circ} \mathrm{C}$ and a snow cover deeper than $1.5 \mathrm{~m}$ (Rossi et al. 2011). The summers are short, with extreme temperatures exceeding $29^{\circ} \mathrm{C}$ in all sites. Soils are podzolic and vary in depth across sites (Rossi et al. 2013a). The organic layer in SIM ranges between 10 and $20 \mathrm{~cm}$, with the maximum rooting depth limited by a shallow bedrock. In the other stands, the organic layer is deeper and reaches $20-40 \mathrm{~cm}$. Soil moisture content is highest in the northern sites due to the higher water holding capacity of the soil, while SIM shows the lowest values (Belien et al. 2014a).

The stand density varied from 1300 to 2150 trees ha ${ }^{-1}$, with the densest being BER (Table 1). The dominant height varied between 18.0 and $20.2 \mathrm{~m}$, and gradually decreased with latitude. Mean DBH (diameter at breast height) was $15.8-19.4 \mathrm{~cm}$, which produced a basal area ranging between 30.1 and $43.5 \mathrm{~m}^{2} \mathrm{ha}^{-1}$. More information on site characteristics are reported in (Rossi et al. 2013b)

\section{Experimental design}

In each stand, five transparent plastic under-canopy square-shape roofs with sides of $9.6 \mathrm{~m}$ in length were installed to exclude precipitation from the ground and reduce soil moisture during the growing 
seasons 2010-2012. Overall, a minimum of $180 \mathrm{~m}^{2}$ per stand was covered by the plastic roofs. The majority of the black spruce root system is localized within a distance of 90-200 cm from the stem collar (Polomski and Kuhn 1998). The plastic roofs were thus extended for at least $3 \mathrm{~m}$ from the stem of trees and drained the rain into sinking points in the soil to avoid water flowing back towards the stem (Belien et al. 2012). The plastic roofs were installed in late May and removed in September to avoid the roots freezing during winter due to lack of insulation by the snow.

The soil volumetric water content (VWC) was measured weekly beneath and outside the plastic roofs to verify the effect of the treatment on soil moisture. VWC was measured with a portable device equipped with two probe heads of $20 \mathrm{~cm}$ in length (Fieldscout TDR 100, Spectrum Technologies, Plainfield, IL) in forty points selected at a distance of $1 \mathrm{~m}$ from the stem. All VWC measurements were divided by the maximum observed value at the site to standardize results.

\section{Sampling and data collection}

Sampling was performed at the end of the third year of treatment, in September 2012, in the soil beneath control and treated trees. Control trees were of similar size to treated trees and were growing in the study stands within $50 \mathrm{~m}$ of the experimental plastic roofs. Between 9 and 14 soil cores were randomly collected per site at a distance of $150 \mathrm{~cm}$ from the root collar (Table 2), sealed in plastic bags, immediately transported to the lab, and stored at $-10^{\circ} \mathrm{C}$ in the dark. Cores were collected with a hand auger from the organic horizon, where the majority of black spruce fine-root production occurs (Ruess et al. 2003). Cores were $4.5 \mathrm{~cm}$ in diameter, with a length of 10-18 cm, corresponding to the depth of the organic horizon in the sites.

On average, 52 root fragments for each site and treatment were randomly chosen among those with undamaged and fully-developed apical tips (Table 2) and were carefully cleaned in water under a 
stereo-microscope. Between 10 and 20 root tips located at the distal portion of the fragment (i.e. situated away from the point of attachment) and representing the last-formed apexes of each root were chosen and classified as vital or non-vital (Rossi et al. 2013a). A preliminary power analysis was performed on sub-samples, which optimized resource use and identified the smallest suitable sampling size to be selected in terms of root tips. The sampling size resulting from the power analysis was doubled in the final sampling to improve the representativeness of the results. The distal tips, those more recently produced, were chosen in each root fragment to represent the response to the treatment. Non-vital tips showed a scurfy surface, with an easily detachable cortex. Non-vital ECM had a desiccated and friable appearance, sometimes showing missing parts. Vital tips and ECM were welldeveloped, turgid and inflated. The vital tips were classified as mycorrhized or non-mycorrhized according to whether the ECM mantle was present or lacking, respectively. The systems deriving from ECM ramification were counted as one ECM, irrespective of the extent of ramification (Rossi et al. 2013a). Damaged or not fully developed root tips were excluded from the observations. All observations were made under a stereo-microscope at magnifications of $\times 6-60$ and completed within twelve months of sampling. Magnifications of $\times 100-400$ under light microscope were used for a subsample of root tips and only when identification of ECM mantle was difficult or uncertain.

\section{Statistics}

Generalized Linear Mixed Models were performed in SAS 9.4 (SAS Institute Inc., Cary, NC) for testing the effect of the treatment on the proportion of vital and ECM root tips with data pooled per soil core. GLMM were modelled with logit-link functions, where the response variable was implemented as the ratio between number of events (e.g. number of vital tips) and number of trials (e.g. total number of observed tips). The SLICE procedure in SAS was used to analyze the interaction site $\times$ treatment to test 
the effects of the treatment for each site. The variables site and soil core were used as fixed and random factor, respectively. 


\section{RESULTS}

\section{Soil moisture}

Soil moisture differed in sites (Figure 1). MIS and DAN were the wetter sites, with an average VWC of 51.4 and 51.5\%, respectively. SIM and BER had VWC ranging between 30.2 and 31.4\%. The treatment markedly reduced soil moisture beneath the plastic roofs. On average, VWC was reduced by $68.8 \%$, reaching percentages of between 10.7 and 33.0\%. After the removal of the plastic roofs, the soil under the treated trees required several weeks to attain the same VWC as the control (Figure 1).

\section{Root tip vitality and ECM}

A total of 6,654 root tips were observed and classified according to their vitality and presence of ECM (Table 2). Overall, vital root tips represented $64.4 \pm 15.2 \%$ of the roots analysed (Figure 2). On average, $58.0 \pm 28.1 \%$ of the root tips were associated with ECM, and $71.3 \pm 15.4 \%$ of these were vital. The sites could be separated in two groups: MIS and BER, with a lower proportion of ECM root tips, and SIM and DAN, with a higher proportion. This generated a bimodal data distribution for ECM root tips resulting in a high dispersion. The influence of the stand basal area and density on the proportion of vital and ECM root tips was tested but no significant effect of these factors was observed.

In all sites, the proportion of vital and non-vital tips changed according to the presence of ECM (Figure 3), as also confirmed by the GLMM ( $\mathrm{F}=10.27, \mathrm{DF}=136, \mathrm{p}<0.0001)$. On average, $85.1 \%$ of the ECM tips were vital, while vital tips decreased to $39.8 \%$ when ECM was lacking. DAN showed the least difference between non-ECM and ECM root tips (Figure 3). 


\section{Effect of the treatment of rain exclusion}

Overall, the proportions of the measured variables differed between sites and with treatment (Table 3 and Figure 4). A significant effect of the treatment was observed on the vitality of root tips, which decreased from 68.4 to $61.1 \%$ on average. According to the significant interaction site $\times$ treatment, the effect of the treatment differed between sites, with no effect found in DAN ( $F=0.39, p>0.05$, Table 4).

Rain exclusion modified the presence of ECM (Figure 4 and Table 3). ECM were less frequent on root tips of treated trees, with a variation in their proportion from 63.7 to $55.7 \%$. Although the effect was significant in all sites $(\mathrm{p}<0.05$ or lower, Table 4$)$, the variation in the proportion of ECM root tips was not homogeneous between sites $(\mathrm{F}=6.44, \mathrm{p}<0.01$, Table 3$)$.

The proportion of vital ECM was reduced from 73.8 to $68.6 \%$ on average (Figure 4). The significant interaction site $\times$ treatment revealed the presence of divergent effects of rain exclusion on vital ECM (Table 3). Vital ECM were significantly reduced by the treatment in BER and MIS (F=7.52 and 22.71, respectively), while no change was observed in vital ECM of SIM and DAN (F=0.01 and 1.18, respectively, and $\mathrm{p}>0.05$ ) (Table 4 ). 


\section{DISCUSSION}

This study describes an experiment of rain exclusion conducted for three consecutive years in four black spruce stands representative of the eastern Canadian boreal forest. The plastic roofs installed during the growing season markedly affected soil moisture, with volumetric water content being reduced from c.a. 40 to $21 \%$ on average. As a consequence, treated trees showed a significant decrease in vital root tips and ECM. The proportion of vital ECM was also globally reduced, but significant variations were only detected in two sites. The results confirmed the expectation that roots of black spruce are sensitive to moisture stress. The initial hypothesis that a modification of the soil moisture would reduce the proportion of living roots and ECM located in the superficial soil layers was thus confirmed.

A lower proportion of vital root tips was detected in trees subjected to rain exclusion following the reduction in soil moisture, although the effects were significant only on three stands. These findings are in agreement with previous results showing that drought significantly increases fine root mortality and biomass (Cudlin et al. 2007; Gaul et al. 2008; Lehto and Zwiazek 2011). The dynamics of fine roots, in terms of rate of production, death and turnover, differ along moisture gradients, with more living roots being observed in wet stands (Persson 1983). Biomass of fine roots of Pinus oaxacana was reduced by $60 \%$ during drought years (Valdés et al. 2006). Measurements of stem shrinking and swelling, which represented depletion and replenishment of the water reserves within the studied black spruces, indicated that at night the trees were still partially able to recover the water lost by transpiration during the day (Belien et al. 2014a). According to these measurements, treated trees began to diverge significantly from controls in the third year of treatment, as a possible cumulative effect of rain exclusion on the water status of the plants (Belien et al. 2014a). As black spruce is unable to absorb water through its needles (Belien et al. 2014b), all water for the night-time replenishment of stem 
reserves must necessarily be conducted through its roots. We hypothesize that the observed modifications to the balance between water loss by evapotranspiration and water acquisition from root absorption could be related to the measured decline in vitality of fine roots located in the superficial soil layers.

ECM are essential partners for their contribution to plant nutrition and protection against parasites, and in particular for improving the tolerance to water stress (Smith and Read 2008). Consequently, modifications in root colonization by ECM may in the long run lead to negative effects for boreal tree species during drought events. The treatment could have influenced the presence and vitality of ECM in three ways. First, fungi are organisms adapted to live preferentially in moist but aerobic conditions (Thormann et al. 1999). A decrease in soil moisture results in a less favorable environment for hyphal growth, thus directly affecting the development or renewal of ECM located in the superficial soil layers (Nilsen et al. 1998). Second, symbionts are one of the main carbon sinks of boreal trees (Staddon et al. 2002). If, on the one hand, mycelial strands and hyphae improve the ability of the root system to explore the soil and acquire resources, on the other, ECM have to be regularly provided with carbon in order to be maintained. The treatment may have affected the performance of trees that, under a limited water availability, may have reduced their photosynthetic capacity. A reduction in ECM colonization could thus be indirectly related to the low soil moisture though a reduction of the carbon allocated to root symbionts (Swaty et al. 2004). The physiological traits of trees in SIM and BER, the two southern sites, were reported in a previous paper (Belien et al. 2012). Despite an evident reduction in midday and predawn water potential during the period of rain exclusion, the photosynthetic rate was often similar between treated and control trees, and no reduction in radial growth was observed at the end of the first year of the experiment. However, the physiological measurements performed were not sufficient to produce a more complete carbon budget at tree level. Third, the treatment had partially modified other important features of the environment. Litterfall was completely excluded by the plastic 
roofs, and a substantial reduction of understory plants was observed in the treated areas. These changes may have altered the quality of the organic matter and its decomposition, with potential effects on the ECM organisms.

The treatment was designed to prevent rain reaching the soil and roots. Although the soil moisture conditions were substantially reduced, previously published measurements of stem rehydration demonstrated that water could be still partially accessible (Belien et al. 2014a). The results were thus only representative of the soil located within $10-20 \mathrm{~cm}$ from the surface, where most fine-root production occurs (Read et al. 2004), and in the proximity of the stem collar covered by the plastic roofs, which stretched for 3 m or more from the trees. However, woody roots of mature trees can explore the soil for greater distances than those defined in our treatment (Pregitzer et al. 2002). No information was available on potential modifications of biomass allocation towards deeper soil layers or outside the area covered by the plastic roofs for improving the access of roots to other water resources that were not excluded by the treatment. Such adaptation mechanisms are described for other conifer species (Moser et al. 2015; Pregitzer et al. 2002), so may also reasonably occur in black spruce.

The effects of the treatment on vital root tips and vital ECM were not significant in DAN, the northern site, and this confirmed previous observations of ectomycorrhizal colonization that responses to environmental change can be site-specific (Swaty et al. 1998). This stand had the coldest temperatures, the shortest snow-free period and growing season (Rossi et al. 2011). Evapotranspiration processes were generally lower than those of the other sites, the water table was quite superficial, and visible also beneath the plastic roofs at a depth of 30-40 cm (S. Rossi, personal observations). Despite the marked reduction in water content measured in the upper soil layers, water may have been easily available for the other roots. Moreover, root longevity increases with latitude, where soils are colder and nutrient concentration is reduced (Gill and Jackson 2000; Ruess et al. 2003). Thus, the lack of significant results 
for trees in DAN could be related to a slower response at colder and wetter sites. It is important to note that Cenococcum geophilum, an ECM repeatedly described in this study area (Rossi et al. 2012; Rossi et al. 2013a) and abundantly observed in our samples (data not shown), has broad environmental tolerance, and can remain alive even when its appearance is dry and brittle (Pigott 1982a, b; Robertson et al. 2006). Consequently, the presence of this morphotype, associated with the ability of black spruce to adjust its ECM associations with changes in climate (Robertson et al. 2006), could have played a crucial role in affecting the proportion of vital ECM in SIM and DAN, where the effects of the treatment were not significant.

In this study, the presence of ECM was recorded though morphological observations of the mantle enveloping the root tips. Several tree species harbor roots with fungal mantle although they are not considered ectomycorrhizas because lacking in the Hartig net, the structures generating the symbiosis between plant and fungus (Smith and Read 2008). This is the case for Mycelium radicis atrovirens, a parasite species recurrent in the soil of the boreal forest that is also described in association with black spruce, colonizing between 4 and $12 \%$ of the root tips showing a fungal mantle (Richard and Fortin 1974; Rossi et al. 2013a). Thus, a part of the root tips classified as ECM in our results may be considered as without fungal symbiosis. Moreover, some ECM species show thin or transparent mantles that are hardly visible under a stereo-microscope. Consequently, the lack of a systematic identification of the ECM and its Hartig net at anatomical level could be a potential source of error in our estimations. 


\section{CONCLUSIONS}

The features and complex mechanisms producing and maintaining mycorrhizas in the boreal forest make these dynamic symbioses highly sensitive to environmental changes. Trees and their fungal partners are strictly connected and interdependent, and the resulting ECM potentially persistent as long as the environmental conditions remain favourable for growth and high amounts of carbon resources are translocated to the roots. In the boreal forest, fine-roots and ECM are concentrated in the organic layers of the soil profile, a critical position in the case of drought events (Read et al. 2004). The reduction in soil moisture induced by our three-year experiment of rain exclusion in mature stands modified the proportion of black spruce vital root tips and ECM located in the superficial layers of the soil. If associated with the warmer future conditions predicted by the current climate models, these changes could potentially perturb the balance between the water lost by evapotranspiration and that acquired by the roots. Such effects could be more evident in species with shallow root systems like black spruce. 


\section{ACKNOWLEDGMENTS}

This work was funded by the Natural Sciences and Engineering Research Council of Canada and the

Consortium Ouranos. The authors thank E. Belien and F. Gionest for technical support and A. Garside for checking the English text. 


\section{REFERENCES}

Allison, S.D., and Treseder, K.K. 2008. Warming and drying suppress microbial activity and carbon cycling in boreal forest soils. Global Change Biol. 14: 2898-2909.

Becker, C.A., Mroz, G.D., and Fuller, L.G. 1987. The effects of plant moisture stress on red pine (Pinus resinosa) seedling growth and establishment. Can. J. For. Res. 17: 813-820.

Belien, E., Rossi, S., Morin, H., and Deslauriers, A. 2012. Xylogenesis in black spruce subjected to a rain exclusion in the field. Can. J. For. Res. 42: 1306-1315.

Belien, E., Rossi, S., Morin, H., and Deslauriers, A. 2014a. High resolution analysis of stem radius variations in black spruce subjected to rain exclusion for three summers. Trees 28: 1257-1265.

Belien, E., Rossi, S., Morin, H., Deslauriers, A., and Gaudard, J. 2014b. Testing foliar absorption in black spruce [Picea mariana (Mill.) BSP] saplings. American Journal of Experimental Biology 1: 5260.

Cudlin, P., Kieliszewska-Rokicka, B., Rudawska, M., Grebenc, T., Alberton, O., Lehto, T., Bakker, M.R., Børja, I., Konôpka, B., Leski, T., Kraigher, H., and Kuyper, T.W. 2007. Fine roots and ectomycorrhizas as indicators of environmental change. Plant Biosystems 141: 406-425.

Davies, F.T.J., Svenson, S.E., Cole, J.C., Phavaphutanon, L., Duray, S.A., Olalde-Portugal, V., Meier, C.E., and Bo, S.H. 1996. Non-nutritional stress acclimatation of mycorrhizal woody plants exposed to drought. Tree Physiol. 16: 985-993.

Deslippe, J.R., Hartmann, M., Mohn, W.W., and Simard, S.W. 2011. Long-term experimental manipulation of climate alters the ectomycorrhizal community of Betula nana in Arctic tundra. Global Change Biol. 17: 1625-1636.

Easterling, D.R., Meehl, G.A., Parmesan, C., Changnon, S.A., Karl, T.R., and Mearns, L.O. 2000. Climate extremes: observations, modeling, and impacts. Science 289: 2068-2074. 
Gaul, D., Hertel, D., Borken, W., Matzner, E., and Leuschner, C. 2008. Effects of experimental drought on the fine root system of mature Norway spruce. For. Ecol. Manage. 256: 1151-1159.

Gill, R.A., and Jackson, R.B. 2000. Global patterns of root turnover for terrestrial ecosystems. New Phytol. 147: 13-31.

Hofgaard, A., Tardif, J., and Bergeron, Y. 1999. Dendroclimatic response of Picea mariana and Pinus banksiana along a latitudinal gradient in eastern Canadian boreal forest. Can. J. For. Res. 29: 13331346.

Huang, J.-G., Tardif, J., Bergeron, Y., Denneler, B., Berninger, F., and Girardin, M. 2010. Radial growth response of four dominant boreal tree species to climate along a latitudinal gradient in the eastern Canadian boreal forest. Global Change Biol. 16: 711-731.

IPCC. 2013. Climate change 2013: The physical science basis. Contribution of working group I to the fifth assessment report of the intergovernmental panel on climate change. Cambridge University Press, Cambridge, UK.

Lamhamedi, M.S., and Bernier, P.Y. 1994. Ecophysiology and field performance of black spruce (Picea mariana): a review. Ann. For. Sci. 51: 529-551.

Lehto, T., and Zwiazek, J.J. 2011. Ectomycorrhizas and water relations of trees: a review. Mycorrhiza 21: 71-90. doi: 10.1007/s00572-010-0348-9.

Moser, B., Kipfer, T., Richter, S., Egli, S., and Wohlgemuth, T. 2015. Drought resistance of Pinus sylvestris seedlings conferred by plastic root architecture rather than ectomycorrhizal colonisation. Ann. For. Sci. 72: 303-309.

Motha, R.P., and Baier, W. 2005. Impacts of present and future climate variability on agriculture in the temperate regions: North America. Clim. Change 70: 137-164.

Nilsen, P., Børja, I., Knutsen, H., and Brean, R. 1998. Nitrogen and drought effects on ectomycorrhizae of Norway spruce [Picea abies L.(Karst.)]. Plant Soil 198: 179-184. 
Persson, H.A. 1983. The distribution and productivity of fine roots in boreal forests. Plant Soil 71: 87101.

Pigott, C.D. 1982a. Fine structure of mycorrhiza formed by Cenococcum geophilum Fr. on Tilia cordata Mill. New Phytol. 92: 501-512.

Pigott, C.D. 1982b. Survival of mycorrhiza formed by Cenococcum geophilum Fr. in dry soils. New Phytol. 92: 513-517.

Polomski, J., and Kuhn, A.J. 1998. Wurzelsysteme. Eidgenössische Forschungsanstalt für Wald, Schnee und Landschaft, Birmensdorf.

Pregitzer, K.S., DeForest, J.L., Burton, A.J., Allen, M.F., Ruess, R.W., and Hendrick, R.L. 2002. Fine root architecture of nine North American trees. Ecol. Monogr. 72: 293-309.

Read, D.J., Leake, J.R., and Perez-Moreno, J. 2004. Mycorrhizal fungi as drivers of ecosystem processes in heathland and boreal forest biomes. Canadian Journal of Botany 82: 1243-1263.

Richard, C., and Fortin, J.A. 1974. Distribution géographique, écologie, physiologie, pathogénicité et sporulation du Mycelium radicis atrovirens. Phytoprotection 55: 67-88.

Robertson, S.J., Tackaberry, L.E., Egger, K.N., and Massicotte, H.B. 2006. Ectomycorrhizal fungal communities of black spruce differ between wetland and upland forests. Can. J. For. Res. 36: 972-985. Rossi, S. 2015. Local adaptations and climate change: converging sensitivity of bud break in black spruce provenances. Int. J. Biometeorol. 59: 827-835.

Rossi, S., Bordeleau, A., Houle, D., and Morin, H. 2012. Effect of chronic ammonium-nitrate addition on the ectomycorrhizal community in a black spruce stand. Can. J. For. Res. 42: 1204-1212.

Rossi, S., Bordeleau, A., Morin, H., and Houle, D. 2013a. The effects of N-enriched rain and warmer soil on the ectomycorrhizae of black spruce remain inconclusive in the short-term. Ann. For. Sci. 70: $825-834$.

Rossi, S., Morin, H., and Deslauriers, A. 2011. Multi-scale influence of snowmelt on xylogenesis of black spruce. Arct. Antarct. Alp. Res. 43: 457-464. 
Rossi, S., Morin, H., Gionest, F., and Laprise, D. 2013b. Spatially explicit structure of natural stands dominated by black spruce. Silva Fenn. 47: 973.

Ruess, R.W., Hendrick, R.L., Burton, A.J., Pregitzer, K.S., Sveinbjornssön, B., Allen, M.F., and Maurer, G.E. 2003. Coupling fine root dynamics with ecosystem carbon cycling in black spruce forests of interior Alaska. Ecol. Monogr. 73: 643-662.

Smith, S.E., and Read, D.J. 2008. Mycorrhizal symbiosis. Academic Press, London.

Staddon, P.L., Heinemeyer, A., and Fitter, A.H. 2002. Mycorrhizas and global environmental change: research at different scales. Plant Soil 244: 253-261.

Swaty, R.L., Deckert, R.J., Whitham, T.G., and Gehring, C.A. 2004. Ectomychorrizal abundance and community composition shifts with drought: predictions from tree rings. Ecology 85: 1072-1084.

Swaty, R.L., Gehring, C.A., van Ert, M., Theimer, T.C., Keim, P., and Whitham, T.G. 1998. Temporal variation in temperature and rainfall differently affects ectomycorrhizal colonisation at two constrasting sites. New Phytol. 139: 733-739.

Thormann, M.N., Currah, R.S., and Bayley, S.E. 1999. The mycorrhizal status of the dominant vegetation along a peatland gradient in southern boreal Alberta, Canada. Wetlands 19: 438-450.

Valdés, M., Asbjornsen, H., Gómez-Cárdenas, M., Juárez, M., and Vogt, K.A. 2006. Drought effects on fine-root and ectomycorrhizal-root biomass in managed Pinus oaxacana Mirov stands in Oaxaca, Mexico. Mycorrhiza 16: 117-124.

Zhang, X., Hogg, W.D., and Mekis, E. 2001. Spatial and temporal characteristics of heavy precipitation events over Canada. J. Clim. 14: 1923-1936.

Zhang, X., Vincent, L.A., Hogg, W.D., and Niitsoo, A. 2000. Temperature and precipitation trends in Canada during the 20th century. Atmosphere Ocean 38: 395-429. 
Table 1. Location and characteristics of the four study sites of the boreal forest of Quebec, Canada. Diameter at breast height $(\mathrm{DBH})$ is reported as mean \pm standard deviation. Dominant height is the mean height of the 100 trees with larger DBH per hectare.

\begin{tabular}{|c|c|c|c|c|c|c|c|}
\hline Stand & Latitude & Longitude & $\begin{array}{l}\text { Altitude } \\
\text { (m a.s.1.) }\end{array}$ & $\begin{array}{l}\text { Dominant } \\
\text { height }(\mathrm{m})\end{array}$ & $\begin{array}{c}\text { Mean } \\
\text { DBH (cm) }\end{array}$ & $\begin{array}{l}\text { Stand density } \\
\left(\text { trees } \mathrm{ha}^{-1}\right)\end{array}$ & $\begin{array}{l}\text { Stand basal } \\
\text { area }\left(\mathrm{m}^{2} \mathrm{ha}^{-1}\right)\end{array}$ \\
\hline SIM & $48^{\circ} 13^{\prime} \mathrm{N}$ & $71^{\circ} 15^{\prime} \mathrm{W}$ & 338 & 20.2 & $16.7 \pm 4.0$ & 1300 & 30.1 \\
\hline BER & $48^{\circ} 51^{\prime} \mathrm{N}$ & $70^{\circ} 20^{\prime} \mathrm{W}$ & 611 & 20.0 & $15.8 \pm 3.0$ & 2150 & 43.5 \\
\hline MIS & $49^{\circ} 43^{\prime} \mathrm{N}$ & $71^{\circ} 56^{\prime} \mathrm{W}$ & 342 & 19.2 & $17.3 \pm 4.1$ & 1450 & 36.2 \\
\hline DAN & $50^{\circ} 41^{\circ} \mathrm{N}$ & $72^{\circ} 11^{\prime} \mathrm{W}$ & 487 & 18.0 & $19.4 \pm 5.0$ & 1375 & 43.4 \\
\hline
\end{tabular}


Table 2. Sample size in terms of soil cores collected, root fragments analyzed, and root tips observed in the four black spruce sites subjected to reductions in soil moisture by a treatment of rain exclusion.

\begin{tabular}{|c|c|c|c|c|c|c|}
\hline \multirow[b]{2}{*}{ Site } & \multicolumn{2}{|c|}{ Soil cores } & \multicolumn{2}{|c|}{ Root fragments } & \multicolumn{2}{|c|}{ Root tips } \\
\hline & Control & Treated & Control & Treated & Control & Treated \\
\hline SIM & 6 & 5 & 55 & 32 & 685 & 558 \\
\hline BER & 4 & 5 & 25 & 50 & 838 & 890 \\
\hline MIS & 7 & 7 & 72 & 67 & 1251 & 1287 \\
\hline DAN & 5 & 4 & 56 & 60 & 636 & 509 \\
\hline
\end{tabular}


Table 3. F-values and degrees of freedom (DF) of the generalized linear mixed models used for comparing the proportions of vital and ectomycorrhizal (ECM) root tips in sites of the boreal forest of Quebec, Canada subjected to reductions in soil moisture by a treatment of rain exclusion.

\section{Factors of variation}

\begin{tabular}{lcccl} 
Measured variable & DF & Site & Treatment & Site $\times$ Treatment \\
\hline Vital root tips & 35 & $33.77 * * *$ & $39.84 * * *$ & $4.03 *$ \\
ECM root tips & 35 & $297.18^{* * *}$ & $55.33 * * *$ & $6.44 * *$ \\
Vital ECM & 35 & $8.82 * * *$ & $11.49 * *$ & $7.60 * * *$ \\
\hline \multicolumn{5}{c}{$\mathrm{p}<.05, * * \mathrm{p}<0.01, * * * \mathrm{p}<0.001$}
\end{tabular}


Table 4. F-values resulting from the tests of simple effects used to verify the effects of reductions in soil moisture by a treatment of rain exclusion on the proportions of vital and ectomycorrhizal (ECM) root tips for each site of the boreal forest of Quebec, Canada.

\begin{tabular}{lcccc}
\hline & \multicolumn{4}{c}{ F-value } \\
\cline { 2 - 5 } Measured variable & SIM & BER & MIS & DAN \\
\hline Vital root tips & $21.18^{* * *}$ & $5.88^{*}$ & $36.75^{* * *}$ & 0.39 \\
ECM root tips & $41.00^{* * *}$ & $4.83^{*}$ & $7.44^{* *}$ & $9.88^{* *}$ \\
Vital ECM & 0.01 & $7.52^{* *}$ & $22.71^{* * *}$ & 1.18 \\
& & & & \\
\hline$* \mathrm{p}<.05, * * \mathrm{p}<0.01, * * * \mathrm{p}<0.001$ & & & \\
\end{tabular}




\section{CAPTION LIST}

Figure 1. Soil moisture in terms of volumetric water content of the soil measured in the four black spruce sites of the boreal forest of Quebec, Canada subjected to a treatment of rain exclusion. Grey background indicates the period when plastic roofs were installed.

Figure 2. Overall presence of vital and ECM root tips recorded in the four black spruce sites of the boreal forest of Quebec, Canada. Boxes represent upper and lower quartiles, whiskers achieve the 10th and 90th percentiles and the mean and median are drawn as cross and horizontal solid lines, respectively.

Figure 3. Proportions of vital and non-vital tips recorded in roots with and without ECM collected in four black spruce sites of the boreal forest of Quebec, Canada.

Figure 4. Proportions of vital and ECM root tips per soil core recorded in the four black spruce sites of the boreal forest of Quebec, Canada subjected to a treatment of rain exclusion. Bars represent the standard error calculated between samples. 